\title{
Predator Ants of the Date Palm Termite Microcerotermes diversus Silvestri and Effects of ant Morphometric Characteristics on ant Functional Response
}

\author{
Masoud Latifian ${ }^{1,}$, Behzad Habibpour ${ }^{2}$, Brad Kard $^{3}$ \\ ${ }^{1}$ Date Palm and Tropical Fruit Research Center, Horticulture Research Institute, Agricultural Research, Education and Extension \\ Organization (AREEO), Ahvaz, Iran \\ ${ }^{2}$ Department of Plant Protection, College of Agriculture, Shahid Chamran University of Ahvaz, Ahvaz, Iran \\ ${ }^{3}$ Department of Entomology and Plant Pathology, Oklahoma State University, Stillwater, USA
}

Email address:

masoud_latifian@yahoo.com (M. Latifian)

${ }^{*}$ Corresponding author

\section{To cite this article:}

Masoud Latifian, Behzad Habibpour, Brad Kard. Predator Ants of the Date Palm Termite Microcerotermes diversus Silvestri and Effects of ant Morphometric Characteristics on ant Functional Response. American Journal of Entomology. Vol. 2, No. 2, 2018 , pp. 16-22. doi: $10.11648 /$ j.aje.20180202.13

Received: August 25, 2018; Accepted: September 5, 2018; Published: October 4, 2018

\begin{abstract}
Scouting for formicidae presence in Microcerotermes diversus galleries was conducted from March to September 2014 in 10 date palm trees located in the Omaltomire region of Khuzestan Province, Iran. Measurements and morphological observations were made of 20 ant workers. For the in vitro predation test, $M$. diversus nymphs ( $\mathrm{n}=10$ per replicate) were placed in a petri dish. Then, live freshly field-collected worker of ants were added. After $24 \mathrm{~h}$, the number termite nymphs that were fully or partially devoured was determined. Five ants, including Plagiolepis pallescens, Polyrhachis lacteipennis, Pheidole teneriffana, Crematogaster antaris, and Monomorium destructor were predators of termites in date palm orchards. $P$. lacteipennis and P. teneriffana, and P. pallescens, C. antaris, and M. destructor, showed Type II and Type III functional responses, respectively. The highest predation efficiency, and the lowest handing time coupled with the highest attack rate by predators was recorded for P. lacteipennis and P. teneriffana, and C. antaris and M. destructor, respectively. Predator ant characteristics measured include: HL-Head length; HW-head width; SL-scape length; EL-eye length; PW-pronotal width; WLthorax length; GL-gaster length; TL-total length; FL-femur length. HL, HW, SL, EL and FL showed positive effects on the functional response parameters. Results showed that termite defense capabilities declined with increasing of ant predation efficiency.
\end{abstract}

Keywords: Ant Morphology, Date palm, Predatory Ants, Termites

\section{Introduction}

Termites are major pests of date palms (Phoenix dactylifera) in Khuzestan Province and surrounding areas. Termites cause considerable damage along the Karon River in Southwest of Iran. Microcerotermes diversus is the dominant species in this region [1]. Abiotic and biotic factors including climate, soil type, garden management practices, and natural enemies are among the most influential factors affecting termite populations $[2,3]$.

Ants (Hymenoptera) are the largest group of predators of termites worldwide [4]. They both share the same habitats and are abundant in terms of biomass and density [5]. Ants and termites have engaged in predator-prey evolutionary relationships during 100 million years of coexistence, with ants developing several predatory tactics and termites responding with several defensive strategies $[4,6,7]$.

Some Harrier ants, including Dorylines and Ponerines, can also quickly destroy a nest of termites [8]. Dorylines cause high mortality in Macrotermes populations. Megaponera ants exhibit discovery capabilities of terrestrial escape channels of Macrotermes subhylinus. Ponerines can embattle thousands of termites in a large nest within a day [9]. Some kinds of ants have the ability to hunt several different termite groups. For example, Brazilian ants can feed on termites from the 
genera Cornitermes, Syntermes, and Coptotermes [10]. Studies on predatory behavior of ants on termites have been conducted similarly for other arthropod predators [11].

One of the important factors that affected hunting success was ratio of predator body size to prey. Arthropod predators often hunt prey smaller than themselves. The ratio of predator-to-prey body length can vary from 100 to 0.3 , and in some cases such as Military ants is $\sim 0.1[12,13]$. Predatorprey interactions are inherently size-dependent. Measurements of body sizes of interacting predators and prey are essential to understanding their feeding relationships, and are increasingly important for food-web studies [14].

In this study the efficiency of predator ants on the dominant termite pest of date palm, M. diversus, was evaluated by comparing ant functional responses. The effects of their morphometric characteristics were analyzed and evaluated relative to their predation ability.

\section{Methods}

\subsection{Study Site}

Investigations were conducted from March through September 2014 on the 'Date Palm and Tropical Fruits Research Center' located in the Omaltomire region of Khuzestan Province, southwest Iran. Ten date palm trees were evaluated during a period of high air temperatures. Study site geographic coordinates are $48^{\circ} 34^{\prime}$ east longitude and $31^{\circ} 14^{\prime}$ north latitude.

\subsection{Sampling}

Ant collections were conducted by scouting for ant presence in $M$. diversus galleries in selected date palm trees. Foraging ants were collected from date palm stems using a porter during low river tide. Collections of ant nests and foragers in galleries were accomplished during high tide by utilizing a boat. The date palm orchards flood during high tides because they are near tidal areas of the Persian Gulf. Due to the low slope of the riverbed, changing the flow of water from the sea to land is a matter of a few meters in the surface. This happens twice a day

\subsection{Identification}

Ants were kept in $75 \%$ alcohol. External features were examined to identify to species. In addition, confirmation of ant identifications was conducted by the Zoology Museum of Iranian Plant Protection Research Institute [15-18].

\subsection{Morphometrics}

Measurements and morphological observations were made of 20 workers from each ant species. For predator ant descriptions, several morphological measurements of different worker characteristics were determined: HL-Head length; HW-head width; SL-scape length; EL-eye length; PW-pronotal width; WL-thorax length; GL-gaster length; TL-total length; FL-femur length [19, 20].

\subsection{Statistics}

To compare measurements and index means among ant populations, analysis of variance (ANOVA) was conducted. Post-hoc comparisons were performed using Bonferroni means comparisons for worker morphometrics.

\subsection{In Vitro Predation}

Groups of $M$. diversus workers $(\mathrm{n}=2,4,8,12$, or 32 per replicate) were contained in a petri dish. One active, freshly field-collected adult of each ant species was then added to each petri dish. For controls, an ant worker, or a late instar $M$. diversus but without the ant predator, were similarly prepared. For each group or control petri dish, the experiment was replicated four times (four petri dishes) and conducted under ambient room conditions $\left(25 \pm 2^{\circ} \mathrm{C} ; 60 \pm 5 \% \mathrm{RH}\right)$. After $24 \mathrm{~h}$, the number of $M$. diversus that were fully or partially devoured was determined for each petri dish.

\subsection{Response Calculations}

The components related to the functional response were calculated using SAS software and the Juliano method for hypothesis testing (Juliano 1993). The type of functional response was selected by logistic regression models. The relationship between the surviving number of worker termite prey $\left(N_{e}\right)$ related to their initial number $\left(\mathrm{N}_{\mathrm{t}}\right)$ was simulated. Hypothesis testing included functional response parameters estimations and comparison of different models. Nonlinear least squares regression was used for this purpose. These techniques were applied to the untransformed data [21]. Holling disc equation (Equation 1) was used for this purpose. Random searching was calculated using Equations 1 and 2 [22].

$$
\begin{gathered}
\text { Equation 1: } N_{e}=\frac{a^{\prime} T N_{t} P_{t}}{1+a^{\prime} T_{h} N_{t}} \\
\text { Equation 2: } N_{e}=N_{t}\left[1-\exp \left(\frac{-a^{\prime} T P_{t}}{1+a^{\prime} T_{h} N_{t}}\right)\right] \\
\text { Equation 3: } N_{e}=\frac{d T P_{t} N_{t}+b T P_{t} N_{t}^{2}}{1+C N_{t}+d T_{h} N_{t}+b T_{h} N_{t}^{2}}
\end{gathered}
$$

In Equations 1, 2 and 3, parameters described as $N_{e}$ equal the number of termites that were exposed to ants, and $N_{\mathrm{t}}$ is the number of termites that were attacked by ants. $P_{t}$ is the number of ants in the test at time $t$, with an instantaneous power search or attack constant or search efficiency, $T$ is total time available to ants, $N_{t}$ is the number of termites in the test at time t, and $T_{h}$ is the handling time [21, 22].

Here, $b, C$ and $d$ are constants in Equation 3. The estimated parameters $\left(a^{\prime} ; T_{h} ; T / T_{h}\right)$ were compared for different numbers of predator ants for assessing predator efficiency. $a^{\prime}$ is the ratio of termites that different predator ants are faced with per unit of available search time. $T_{h}$ means all the actions occurring during predatory time, with 
the exception non-submission, pursuit, cleaning, selfassembly, and relaxation times. $\mathrm{T} / \mathrm{T}_{\mathrm{h}}$ also was the highest attack rate [21].

\subsection{Analysis of Morphometric Characteristics and Functional Response Parameters}

Correlation analysis was conducted between morphometic characters and functional response parameters, including HL, HW, SL, EL, PW, WL, GL, TL, and FL as independent factors, and the functional response parameters including $a^{\prime}$, $T_{h}$, and $T / T_{h}$ as dependent factors. Correlation analysis evaluated the strength of a relationship between two groups of numerical measurements studied in this research. Positive correlation exists if one variable increases simultaneously with the other. Negative correlation exists if one variable decreases while the other increases. Pearson's coefficient is the measurement of correlation and ranges (depending on the correlation) between +1 and $-1 ;+1$ indicate the strongest positive correlation possible, -1 indicates the strongest negative correlation possible. Therefore the closer the coefficient to either of these numbers the stronger the correlation of the data it represents.

\section{Results}

\subsection{Predator Ants}

Five ant species from two subfamilies, five tribes, and five genera were identified (Table 1).

Table 1. Predator ants of M. diversus.

\begin{tabular}{lll}
\hline Subfamily & Tribe & Species \\
\hline \multirow{2}{*}{ Formicinae } & Plagiolepidini & Plagiolepis pallescens Forel \\
& Camponotini & Polyrhachis lacteipennis Smith \\
& Attini & Pheidole teneriffana Forel \\
Myrmicinae & Crematogastrini & Crematogaster antaris Forel \\
& Solenopsidini & Monomorium destructor Jerdon \\
\hline
\end{tabular}

\subsection{Morphometrics}

Measurements for five worker predator ants (Table 2).

Table 2. Average worker measurements of predator ants ${ }^{I}$.

\begin{tabular}{|c|c|c|c|c|c|}
\hline \multirow{2}{*}{ Ant species } & \multicolumn{5}{|c|}{ mean \pm SE, mm } \\
\hline & HL & HW & SL & EL & PW \\
\hline P. pallescens & $1.91 \pm 0.21 \mathrm{a}$ & $1.62 \pm 0.32 \mathrm{a}$ & $2.13 \pm 0.33 a$ & $0.48 \pm 0.06 \mathrm{a}$ & $0.72 \pm 0.04 \mathrm{a}$ \\
\hline P. lacteipennis & $0.82 \pm 0.09 \mathrm{~b}$ & $0.74 \pm 0.05 b c$ & $0.92 \pm 0.05 b c$ & $0.21 \pm 0.02 b$ & $0.32 \pm 0.02 b$ \\
\hline P. teneriffana & $0.43 \pm 0.03 \mathrm{c}$ & $0.35 \pm 0.03 c$ & $0.41 \pm 0.07 \mathrm{c}$ & $0.11 \pm 0.01 \mathrm{c}$ & $0.14 \pm 0.01 \mathrm{c}$ \\
\hline C. antaris & $0.95 \pm 0.08 \mathrm{ab}$ & $0.83 \pm 0.04 \mathrm{~b}$ & $1.12 \pm 0.25 b$ & $0.25 \pm 0.03 b$ & $0.33 \pm 0.02 b$ \\
\hline M. destructor & $0.24 \pm 0.02 \mathrm{~d}$ & $0.21 \pm 0.02 \mathrm{~cd}$ & $0.34 \pm 0.06 \mathrm{c}$ & $0.07 \pm 0.02 \mathrm{c}$ & $0.74 \pm 0.05 \mathrm{a}$ \\
\hline
\end{tabular}

\begin{tabular}{|c|c|c|c|c|}
\hline & \multicolumn{4}{|c|}{ mean \pm SE, mm } \\
\hline & WL & GL & TL & FL \\
\hline P. pallescens & $3.81 \pm 0.41 \mathrm{ab}$ & $2.76 \pm 0.31 \mathrm{a}$ & $8.92 \pm 0.71 \mathrm{a}$ & $3.02 \pm 0.41 \mathrm{a}$ \\
\hline P. lacteipennis & $1.94 \pm 0.22 \mathrm{~cd}$ & $1.42 \pm 0.19 b$ & $4.53 \pm 0.38 \mathrm{c}$ & $1.51 \pm 0.23 b c$ \\
\hline P. teneriffana & $0.92 \pm 0.07 \mathrm{~d}$ & $0.65 \pm 0.07 \mathrm{c}$ & $2.11 \pm 0.29 \mathrm{~d}$ & $0.71 \pm 0.12 \mathrm{c}$ \\
\hline C. antaris & $2.32 \pm 0.51 \mathrm{c}$ & $1.67 \pm 0.12 b$ & $5.47 \pm 0.63 \mathrm{bc}$ & $1.78 \pm 0.37 \mathrm{bc}$ \\
\hline M. destructor & $4.13 \pm 0.43 \mathrm{a}$ & $2.98 \pm 0.61 \mathrm{a}$ & $9.61 \pm 1.02 \mathrm{a}$ & $3.17 \pm 0.49 \mathrm{a}$ \\
\hline
\end{tabular}

${ }^{1}$ Down columns, means followed by the same letter are not significantly different.

Means are not compared across rows

\subsection{Functional Responses}

The mean number of date palm termites consumed by each predator ant species increased significantly as the number of $M$. diversus workers increased. The functional response curves obtained (Figure 1) show variation of predator ant consumption at different termite densities.

If ant density is constant then they can regulate termite density only if they have a type III functional response because this is the only type of functional response for which prey mortality can increase with increasing prey density. However, regulating effect of ant is limited to the interval of termite density where mortality increases. If ant density exceeds the upper limit of this interval, then mortality due to predation starts declining, and predation will cause a positive feed-back. As a result, the number of prey will get out of control. They will grow in numbers until some other factors (diseases of food shortage) will stop their reproduction. This phenomenon is known as escape from natural enemies [23].
The functional response parameters including searchingpredator efficiency $\left(a^{\prime}\right)$, handling time $\left(T_{h}\right)$ and maximum attack rate $\left(T / T_{h}\right)$ were calculated for each predator ant species (Table 3).

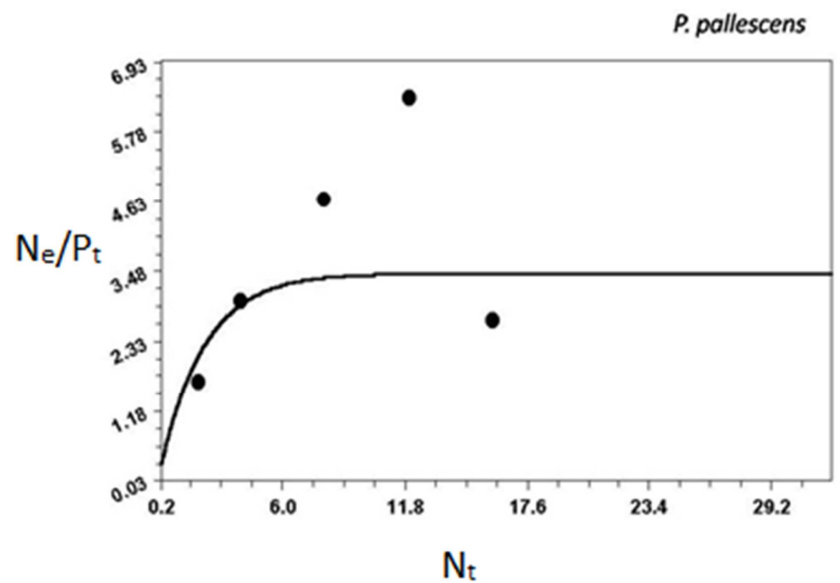



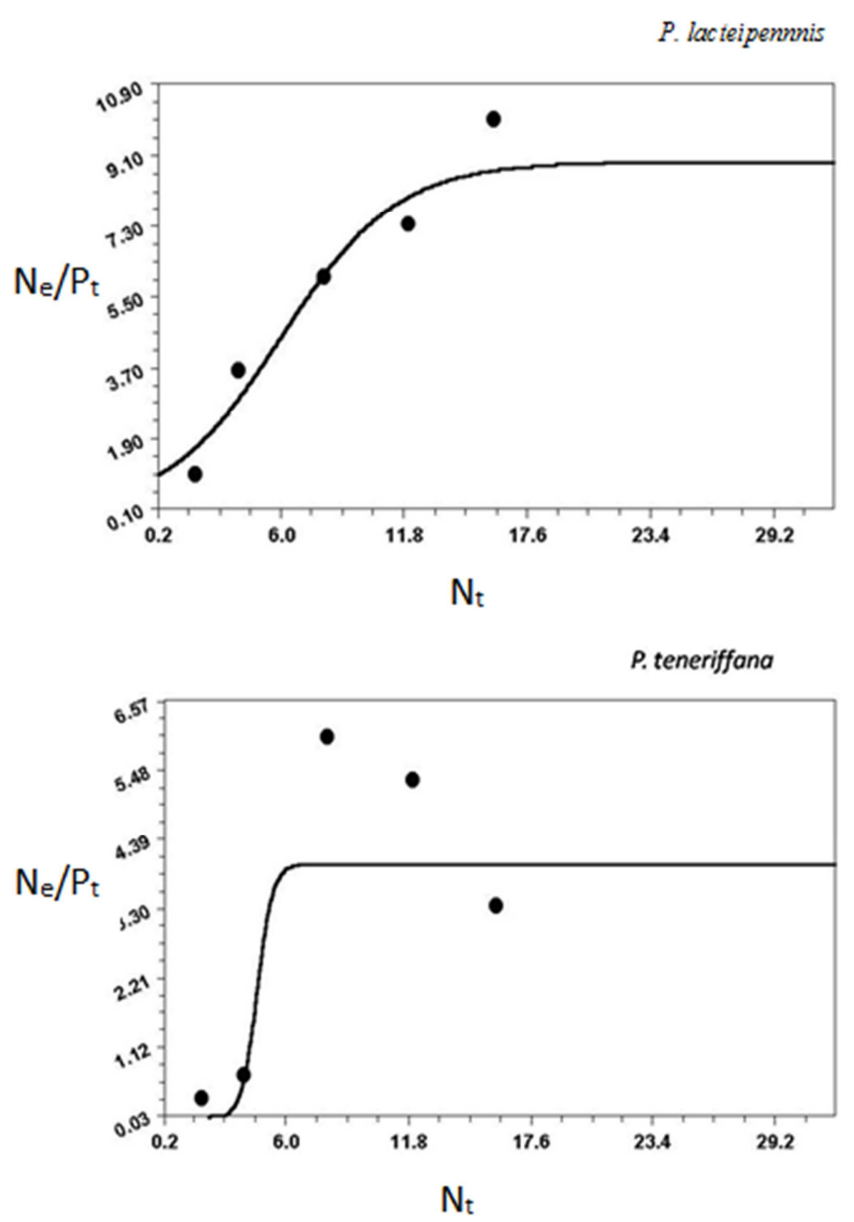

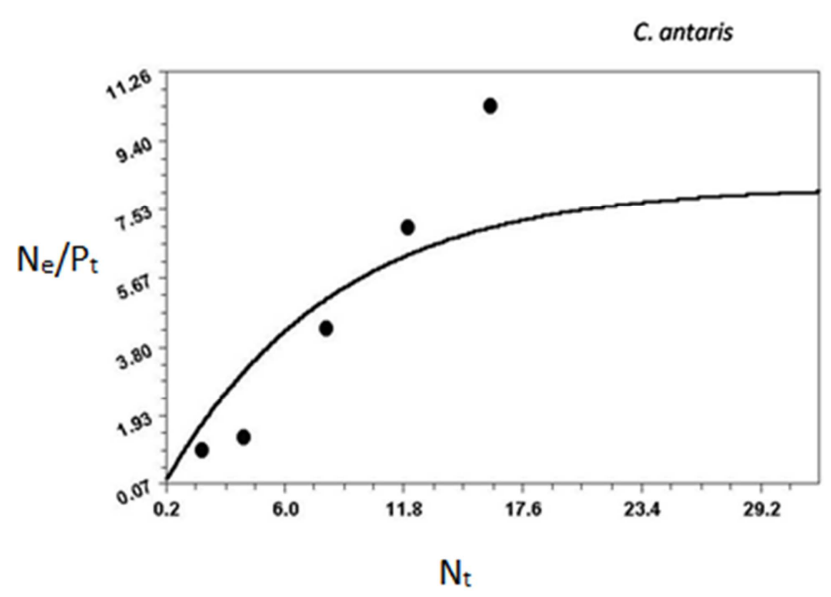

M. destructor

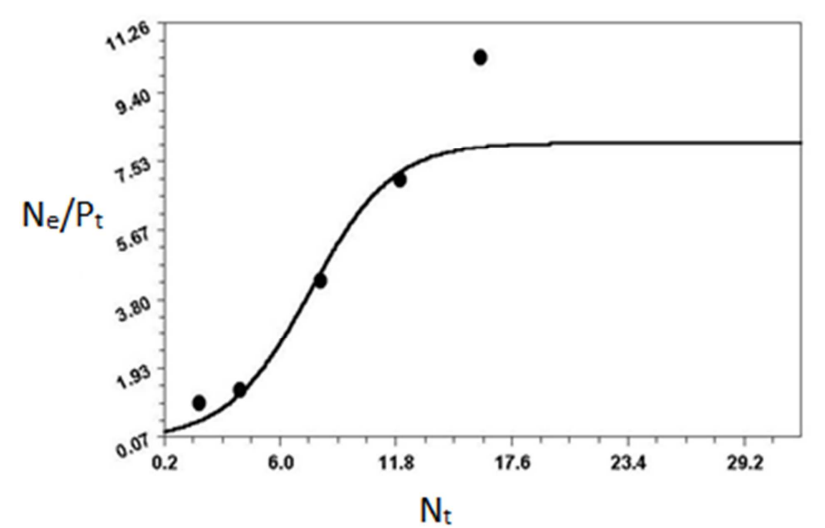

Figure 1. Functional response of the predator ant to the density of $M$. diversus workers ${ }^{1}$.

${ }^{1} N_{t}=$ number of termites in petri dish at time t, 24 hours

$N_{e}=$ number of surviving termites

$P_{t}=$ number of ants in petri dish at time $\mathrm{t}$

Table 3. Functional response parameters for different species of predatory ants ${ }^{l}$.

\begin{tabular}{llllll}
\hline Ant species & $\begin{array}{l}\text { Functional } \\
\text { response type }\end{array}$ & $\begin{array}{l}\text { Determination coefficient } \\
\left(\mathbf{R}^{2}\right)\end{array}$ & Predator efficiency $(\boldsymbol{a})$ & Handling time $\left(\boldsymbol{T}_{\boldsymbol{h}}\right)$ & $\begin{array}{l}\text { Attack rate } \\
\left(\boldsymbol{T} / \boldsymbol{T}_{\boldsymbol{h}}\right)\end{array}$ \\
\hline P. pallescens & Type III & 0.98 & 1.112 & 0.202 & 15.24 \\
P. lacteipennis & Type II & 0.97 & 1.367 & 0.065 & 46.11 \\
P. teneriffana & Type II & 0.66 & 0.358 & 0.068 & 60.58 \\
C. antaris & Type III & 0.82 & 0.884 & 0.235 & 16.74 \\
M. destructor & Type III & 0.61 & 0.932 & 0.041 & 105.97 \\
\hline
\end{tabular}

Type II: increased termite density reduces probability of encountering a predator ant

Type III: predator - prey interactions relatively stable

The functional response of $P$. lacteipennis and $P$. teneriffana are Type II. Therefore, the probability of encountering predators for each individual worker termite was reduced permanently by increasing termite worker densities. P. pallescens, C. antaris, and M. destructor had functional response Type III. Type III indicates stabilizing interactions between predator and prey. The highest and lowest predator efficiencies were shown by P. lacteipennis and $P$. teneriffana, respectively. The minimum handling time was estimated for $P$. lacteipennis, $P$. teneriffana, and $M$. destructor with the maximum handling times attributed to $P$. pallescens and $C$. antaris The highest and lowest attack rates are shown by $M$. destructor respectively. According to the overall results, $M$. destructor is the strongest predatory ant against $M$. diversus. It has the median predator efficiency, but lowest handling time and the highest attack rate compared with the other four predatory ants.

\subsection{Effects of Morphometric Characteristic on the Functional Responses}

Effects of the morphometric characteristics of predatory ants on different behavioral response parameters are shown in Figure 2. 


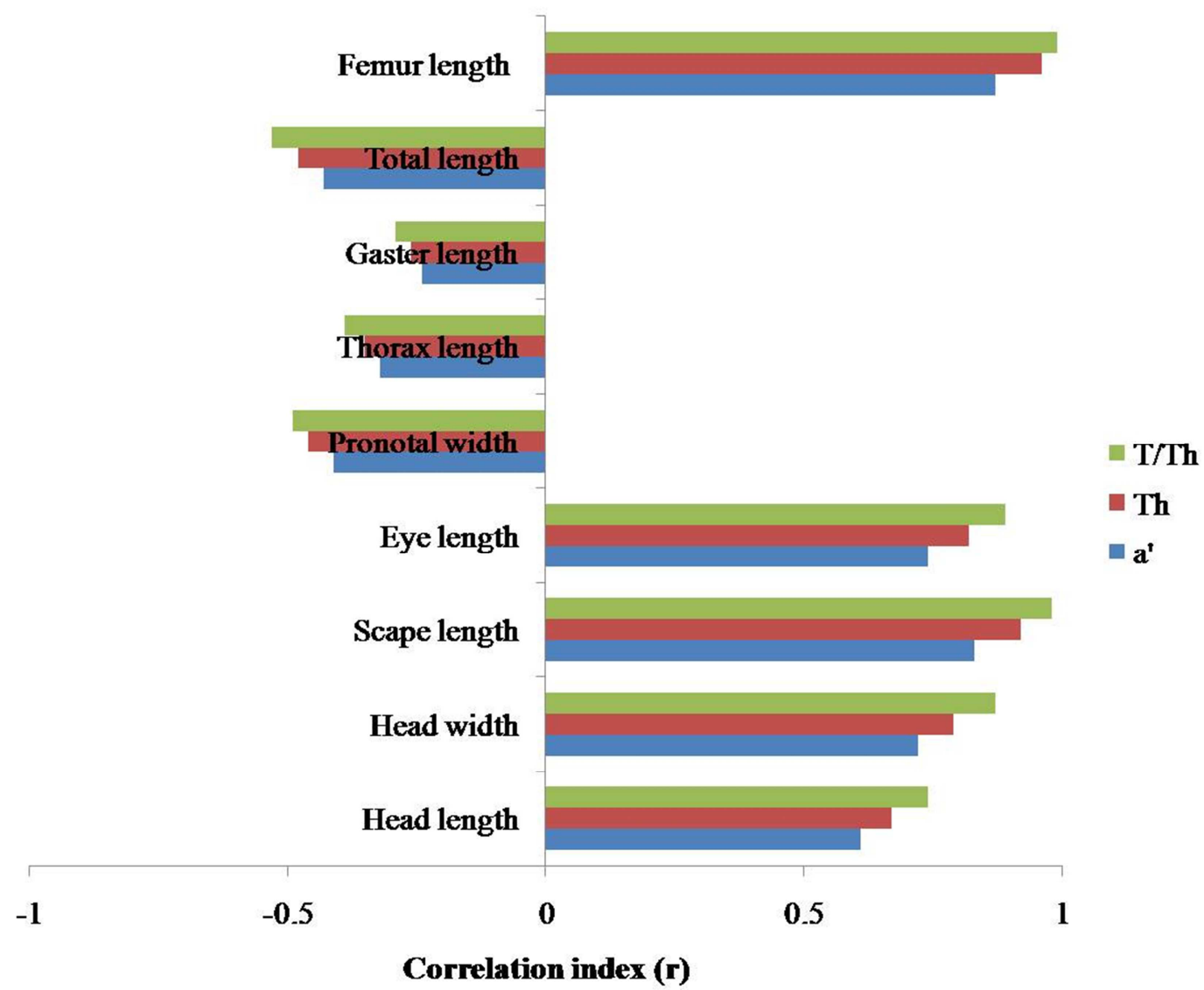

Figure 2. Collerogram of relationships between morphometic characteristics and functional response parameters of predatory ants.

In correlation analysis, we estimate a sample correlation coefficient, more specifically the Pearson Product Moment correlation coefficient. The sample correlation coefficient, denoted $r$, ranges between -1 and +1 and quantifies the direction and strength of the linear association between the two variables. The correlation between two variables can be positive (i.e., higher levels of one variable are associated with higher levels of the other) or negative (i.e., higher levels of one variable are associated with lower levels of the other). The sign of the correlation coefficient indicates the direction of the association. The magnitude of the correlation coefficient indicates the strength of the association.

Morphometric characteristics that are positively correlated with beneficial behavioral response parameters have increased effects on predation efficiency. Characteristics with negatively correlated values have reductive effects on predation ability. Among the positive effects characteristics, FL increased the mobility of ants and therefore enhanced their ability to pursue worker termites. Two characteristics including EL and SL have positive effects on detecting suitable prey. The width and length of the head capsule also have positive effects on behavioral response parameters because they can increase the killing ability of predatory ants. Characteristics such as TL, GL, WL, and PW had negative effects on behavioral responses because they reduced ant mobility. However, these effects were not significant.

\section{Discussion}

Ants are a primary enemy of termites and may affect some termite densities in natural settings. The degree of predation depends on the population of the ant colony compared with termite density and accessibility, and the availability of other food sources for ants [24]. Termites defend their colony from predatory ant attack. The primary physical defense in many termite species is nest construction, which provides shelter and limits access, guarded by a specialized soldier caste using one or a combination of methods: cutting mandibles, abdominal dehiscence, or chemical secretions [25, 26].

With different ant species, predator size is positively correlated with average size of the prey. However, correlations depend on the method and type of hunting [27]. For example, predator ants of subfamilies Myrmeciinae and Ponerinae often choose prey smaller than themselves. Results of this study showed that $P$. teneriffana, $C$. antaris and $M$. destructor consumed date palm termites smaller than themselves. Another group of predatory ants such as Formicinae have self-defense, therefore this group can hunt a wider range of prey sizes than the first group [28]. $P$. lacteipennis and $P$. teneriffana showed similar predator efficiency in this study. Other studies have shown that some species of the subfamily Dolichoderine can hunt prey individuals up to 15 times larger than themselves [29]. 
Results of this study show a positive relationship between increasing predator efficiency and some characteristics of body size. Increased some characteristics of body size enhances the ability of predatory ants to hunt date palm termites Predatory ants have the ability to consume $M$. diversus as soft-bodied termite have little ability to defend themselves. Predation efficiency improved with increasing some part of ant body size including eye length, scape length, head width and Head length.

Ants must move at a speed that can be sustained for long periods in a manner that is energetically efficient [30]. In terms of energy economy, an increase in the size of all body parts may not have equal effects in increasing the predator efficiency. Characteristics such as eye, femur, and head size positively correlated with predation efficiency.

\section{Conclusion}

Ant body size is important in terms of the size of prey consumed [31]. Predator body size has a complex relationship with prey size, and it affects ecological characteristics including distribution capacity, competitive ability, and the risk of natural enemies [32, 33]. Several species of ants are active in date palm gardens. Although a study on the role of predatory ants has not yet been conducted on population fluctuation of date palm termites in field conditions, overall, predatory ants appear to have an important role in mortality and natural control of date palm termites.

\section{References}

[1] Rad B, Latifian M (2005) Identification, distribution, and importance degree of date palm injurious termites and study of the population fluctuation of dominant species in Khuzestan Province. Agricultural Scientific Information and Documentation Centre, Agricultural Research and Education Organization, Iran. http://agrisis.areo.ir/ HomePage.aspx?

$\mathrm{abID}=15589 \&$ Site $=$ agrisis. areo $\&$ Lang $=$ en-US

[2] Dauber J, Hirsch M, Simmering D, Waldhardt R, Otte A, Wolters V (2003) Landscape structure as an indicator of biodiversity: Matrix effects on species richness. Agric Ecosys Environ 98:321-329.

[3] Dauber J, Purtauf T, Allspach A, Frisch J, Voigtlander K, Wolters V (2005) Local vs landscape controls on diversity: A test using surface dwelling soil macroinvertebrates of different mobility. Global Ecol Biogeogr 14:213-221.

[4] Hölldobler B, Wilson EO (1990) The Ants. Belknap Press of Harvard Univ Press, Cambridge. 746pp.

[5] Fujiwara-Tsujii N, Cheong CH, Maryati M, Yamaoka R (2006) Identification of a potent termite repellent from the Bornean Dolichoderine ant Dolochoderine sulcaticepus (Hymenoptera: Formicidae). J Trop Biol Conserv 2(1):71-78.

[6] Deligne J, Quennedey A, Blum MS (1981) The enemies and defense mechanisms of termites. pp 1-76. In HR Hermann (ed), Social Insects, vol. 2, Academic Press, New York.

[7] Mill AE (1983) Behavioral and toxic effects of termite defensive secretions on ants. Physiol Entomol 8:413418.

[8] Higashi S, Ito F (1989) Defense of termitaria by termitophilous ants. Oecologia 80(2): 145-147. Accessed from http://www.jstor.org/ stable/4219024

[9] Abe Y, Bignell DE, Higashi T (2014) Termites: Evolution, Sociality, Symbioses, Ecology. Springer, Aban 23, 1393 AP-Science. 466 pp.

[10] Pearce MJ (1997) Termites: biology and pest management. CABI Publishing. 172p.

[11] Egonyu, JP, Baguma J, Ogari I, Ahumuza G, Kyamanywa S, Kucel P, Kagezi GH, Erbaugh M, Phiri N, Ritchie BJ, Wagoire WW (2015) The formicid ant, Plagiolepis sp., as a predator of the coffee twig borer, Xylosandrus compactus. Biol Contr 91:42-46.

[12] Brose U (2010) Body-mass constraints on foraging behavior determine population and food-web dynamics. Funct Ecol 24:28-34.

[13] Nakazawa T, Ohba S-y, Ushio M (2013) Predator-prey body size relationships when predators can consume prey larger than themselves. Biol Letters 9(3):20121193. doi: 10.1098/rsbl.2012.1193

[14] Yvon-Durocher G, Ress J, Blanchard J, Ebenman B, Perkins DM, Reuman DC, Thierry A, Woodward G, Petchey OL (2011) Across ecosystem comparisons of size structure: methods, approaches and prospects. Oikos 120:550-563. doi: 10.1111/j.1600-0706. 2010.18863 .

[15] Creighton WS (1950) Ants of North America. Bull Museum Comp Zool 104:402-410.

[16] Alipanah H, Kharazi-Pakdel A, Moghadassi P (1995) Taxonomical study of Myrmicinae ants in Tehran. Proc $12^{\text {th }}$ Iranian Plant Protection Congress, p. 304. [Persian with English abstract]

[17] Fellowes JR (1999) Exotic ants in Asia: is the mainland at risk? The case of Hong Kong. Aliens 9:5-6.

[18] Bolton, B, Alpert G, Ward PS, Naskrecki P (2006) Bolton's Catalogue of Ants of the World: 1758-2005. Harvard University Press, Cambridge.

[19] Trager JC (1984a) A revision of the genus Paratrechina (Hymenoptera: Formicidae) of the continental United States. Sociobiol 9(2):51-162.

[20] Trager JC (1984b) A revision of the genus Paratrechina (Hymenoptera: Formicidae) of the continental United States. Ph.D. Dissertation, Univ Florida.

[21] Juliano SA (1993) Nonlinear curve fitting: predation and functional response curves. pp 159-182. In SM Scheiner and J Gurevitch (eds), Design and Analysis of Ecological Experiments. Chapman \& Hall, London. 445pp.

[22] Holling CS (1966) The functional response of invertebrate predators to prey density. Memoires Entomol Soc Canada 98(S48):5-86. doi: 10.4039/entm9848fv. 
[23] Angelani, L (2012) Collective predation and escape strategies. Physical review letters, 109 (11): 104-118.

[24] Xiao-Lan W, Ping W, Cecilia AL, Dahlsjö D SillamDussès, Šobotník J (2017) Breaking the cipher: ant eavesdropping on the variational trail pheromone of its termite prey.Proc R Soc Lond B 284(1853):20170121.

[25] Noirot C, Darlington JPEC (2000) Termite nests: architecture, regulation and defense. $\mathrm{pp}$ 121-139. In $\mathrm{T}$ Abe, DE Bignell, M Higashi (eds), Termites: Evolution, Sociality, Symbioses, Ecology. Kluwer, Dortdretch, The Netherlands.

[26] Gromysz-Kalkowska K, Unkiewicz-Winiarczyk A (2010) Ethological defense mechanisms in insects. I. Passive defense. Annals UMCS Biologia 65:15-27.

[27] Sabelis MW (1992) Predatory arthropods. In MJ Crawley (ed), Natural Enemies: The Population Biology of Predators, Parasites and Diseases, Chapt 10. Blackwell Scientific Publications, Oxford. doi 10.1002/9781444314076.ch10.
[28] Kaspari M, Weiser M (1999) The size-grain hypothesis and interspecific scaling in ants. Funct Ecol 13:530-538.

[29] Traniello JFA (1989) Foraging strategies of ants. Ann Rev Entomol 34:191-210.

[30] Biewener AA (2003) Animal locomotion. Oxford University Press, Oxford.

[31] Mertl AL, Traniello JFA (2009) Behavioral evolution in the major worker sub-caste of twig-nesting Pheidole (Hymenoptera: Formicidae): does morphological specialization influence task plasticity? Behavioral Ecol Sociobiol 63:1411-1426.

[32] Hölldobler B, Wilson EO (2009). The Superorganism: The Beauty, Elegance, and Strangeness of Insect Societies. WW Norton \& Company, New York. 521pp.

[33] Lach L, Parr CL, Abbott KL (2010) Ant Ecology. Oxford University Press, Oxford. 432pp. 